\title{
Prediction of Load-Carrying Capacity in Steel Shear Wall with Opening Using Artificial Neural Network
}

\author{
E. Khalilzadeh Vahidi ${ }^{1}$ and M. M. Roshani ${ }^{2}$ \\ ${ }^{1}$ Civil Engineering Department, Razi University, Kermanshah 671497346, Iran \\ ${ }^{2}$ Young Researchers and Elite Club, Islamic Azad University, Kermanshah Branch, Kermanshah 6718997551, Iran \\ Correspondence should be addressed to E. Khalilzadeh Vahidi; e_vahidi2000@yahoo.com
}

Received 17 November 2015; Revised 1 February 2016; Accepted 22 February 2016

Academic Editor: Francis T. K. Au

Copyright ( 2016 E. Khalilzadeh Vahidi and M. M. Roshani. This is an open access article distributed under the Creative Commons Attribution License, which permits unrestricted use, distribution, and reproduction in any medium, provided the original work is properly cited.

\begin{abstract}
The effects of different parameters on steel plate shear wall (SPSW) are investigated. The studied parameters are thickness of plate, location of the opening, thickness of diagonal stiffeners, and thickness of circular stiffener. Load-carrying capacity of the SPSW is studied under static load using nonlinear geometrical and material analysis in ABAQUS and the obtained simulation results are verified. An artificial neural network (ANN) is proposed to model the effects of these parameters. According to the results the circular stiffener has more effect compared with the diagonal stiffeners. However, the thickness of the plate has the most significant effect on the SPSW behavior. The results show that the best place for the opening location is the center of SPSW. Multilayer perceptron (MLP) neural network was used to predict the maximum load in SPSW with opening. The predicted maximum load values using the proposed MLP model were compared with the simulated validated data. The obtained results show that the proposed ANN model has achieved good agreement with the validated simulated data, with correlation coefficient of more than 0.9975. Therefore, the proposed model is useful, reliable, fast, and cheap tools to predict the maximum load in SPSW.
\end{abstract}

\section{Introduction}

In the current seismic resistant design, building structures are allowed to exceed their elastic limit under severe earthquake excitation. However, brittle collapse of a building should be prevented. Besides strength requirements, stiffness is another concern in a structural design. With high strength and high stiffness, the steel plate shear wall has drawn many engineers' attention. Many research works have been carried out on the steel plate shear walls. One of the attractions of steel plate shear walls, SPSWs, is the easiness of opening application in the infill plate, sometimes required for passing the utilities, architectural purposes, or structural reasons. Experimental studies have been carried out on the thin steel plate shear walls by Caccese et al. [1], Driver et al. [2], and Lubell et al. [3]. Analytical studies on the shear buckling behavior of steel plate wall and the behavior of a multistory steel wall system were conducted by Elgaaly et al. [4, 5], Driver et al. [6], Berman and Bruneau [7], and Sabouri-Ghomi et al. [8]. Design rules of the thin steel plate shear wall are also specified in the design specifications, such as AISC [9] and CSA [10]. In [11], several experiments have been performed on the behavior and energy absorption coefficients of ductile SPSW with stiffeners and without stiffeners. The obtained results in this approach show that behavior coefficients of the SPSW with stiffeners and without stiffeners are 11.5 and 12.2, respectively. Energy absorption of the SPSW without stiffeners is 36\% lower than that of SPSW with stiffeners. Another experiment has been carried out on the SPSW with and without opening. The experiments are performed on the 3 one-story specimens with $1 / 2$ scaled under the quasistatic loading. The first specimen has no stiffeners, while the second specimen has diagonal stiffeners. The third specimen has both diagonal stiffeners and the opening. The results show that shear strength of the SPSW with opening and stiffeners is close to that of the SPSW without opening and the stiffeners. When the circular and diagonal stiffeners are used in the SPSW, the energy absorption is $14 \%$ more compared with conditions in which the opening and the stiffeners are not considered. An experiment on the SPSW with thin shield and connecting 


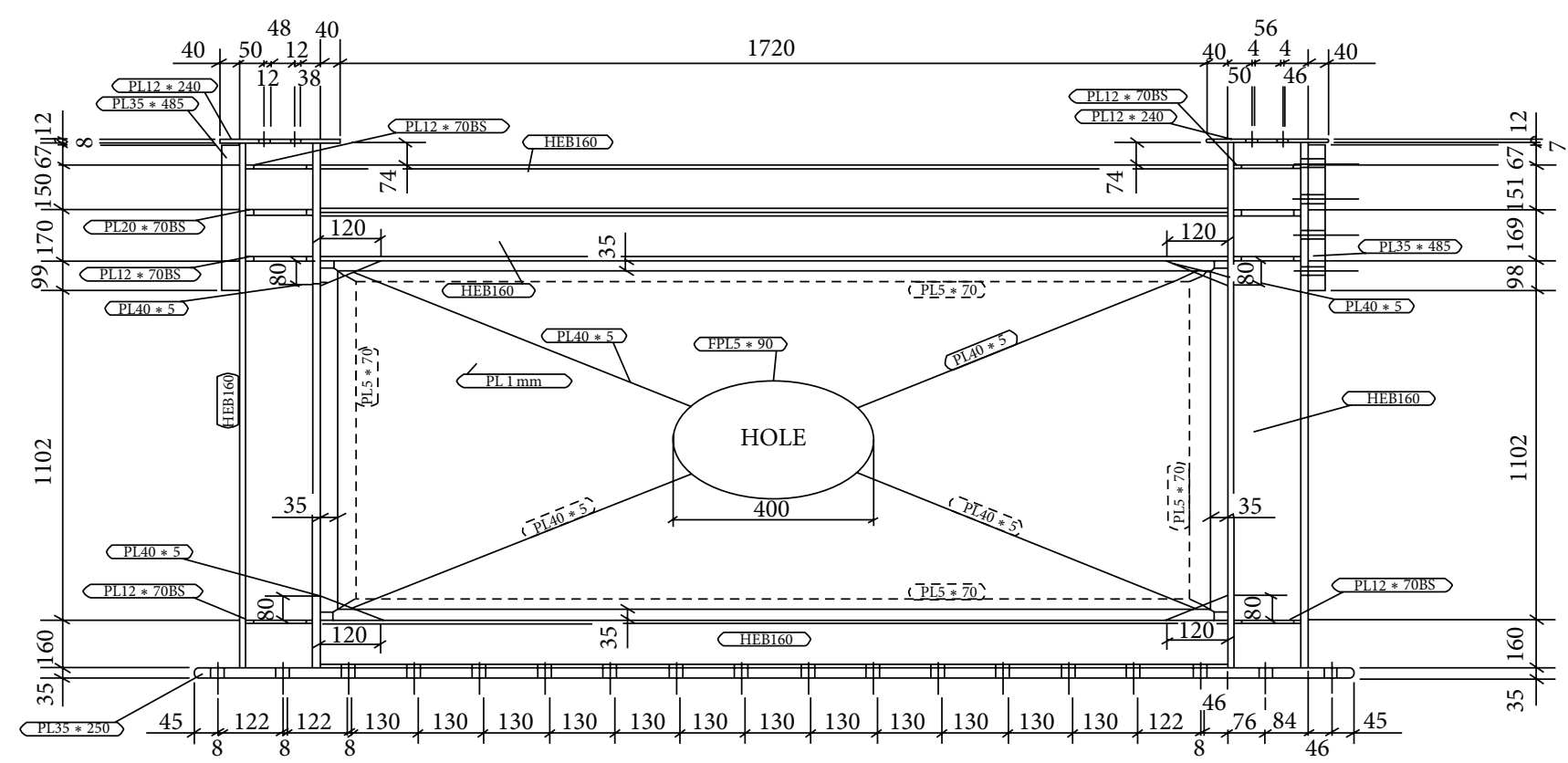

FIGURE 1: Perforated specimen SPSW $\left(\mathrm{s}_{4}\right)$ details [12].

TABLE 1: Mechanical proprieties of steel materials from the tension coupon tests [12].

\begin{tabular}{|c|c|c|c|c|c|c|c|}
\hline Steel material & $\begin{array}{c}\text { Elastic modulus } \\
(\mathrm{MPa})\end{array}$ & $\begin{array}{c}\text { Static yield } \\
(\mathrm{MPa})\end{array}$ & $\begin{array}{l}\text { Static ultimate } \\
\quad(\mathrm{MPa})\end{array}$ & $\begin{array}{c}\text { Yield strain } \\
(\mathrm{MPa})\end{array}$ & $\begin{array}{l}\text { Hardening } \\
\text { strain (\%) }\end{array}$ & $\begin{array}{c}\text { Ultimate } \\
\text { strain (\%) }\end{array}$ & $\begin{array}{c}\text { Rupture } \\
\text { strain (\%) }\end{array}$ \\
\hline $\begin{array}{l}\operatorname{HEB160} \\
\operatorname{SPSW}\left(\mathrm{s}_{1}, \mathrm{~s}_{4}\right)\end{array}$ & $2.06 E+05$ & 340 & 450 & 0.17 & 1.8 & 14.4 & 16.2 \\
\hline $\begin{array}{l}\text { HEB160 } \\
\left(\text { SPSW }_{2}\right)\end{array}$ & $2.07 E+05$ & 400 & 450 & 0.19 & 2.7 & 13.2 & 15.1 \\
\hline $\begin{array}{l}\text { Plate } \\
(\mathrm{THK}= \\
5 \mathrm{~mm})\end{array}$ & $2.05 E+05$ & 340 & 470 & 0.17 & 3.06 & 20.5 & 22.3 \\
\hline $\begin{array}{l}\text { Plate } \\
(\mathrm{THK}= \\
4 \mathrm{~mm})\end{array}$ & $2.05 E+05$ & 460 & 550 & 0.22 & 2.67 & 19.1 & 20.8 \\
\hline $\begin{array}{l}\text { Plate } \\
(\mathrm{THK}=0.8 \& \\
1 \mathrm{~mm})\end{array}$ & $2.04 E+05$ & 280 & 500 & 0.14 & 0.3 & 21.6 & 27.0 \\
\hline
\end{tabular}

beams is performed in [12]. The 4 specimens with $1 / 2$ scaled under cyclic and static loading are used in this work. Rigid and semirigid connections are used and compared in this approach. The results show that using semirigid connections of beams as well as column reduces final carrying capacity compared with the rigid connections. The loading capacitance is decreased, where the connecting beams are used [13].

In this study, according to the existence results from an experimental set-up [12], simulation is done using ABAQUS software. The results of the mentioned simulation are validated using experimental data. After the simulation validation, the effect of thickness of plate, location of the opening, thickness of diagonal stiffeners, and thickness of circular stiffener on the load-carrying capacity and absorbed energy is investigated. MLP neural network is used to predict the maximum load and absorbed energy. For developing of the proposed model, the input parameters are thickness of plate $(\mathrm{mm})$, thickness of ring $(\mathrm{mm})$, thickness of stiffener $(\mathrm{mm})$, and location of opening (up, middle, and down) and the outputs are absorbed energy and maximum load.

\section{Validation and Modeling}

Several analyses have been performed, in order to obtain a precise numerical model which verifies the experimental results. The experimental specimen in [12] is considered which is shown in Figure 1. HEB160 profile is used to create the border components (beams and columns). The thickness of SPSW is considered $0.8 \mathrm{~mm}$, while the thickness of beams and columns stiffeners is assumed $5 \mathrm{~mm}$. The applied materials specifications which are used to make beams, columns, stiffeners, and the SPSW are given in Table 1. 


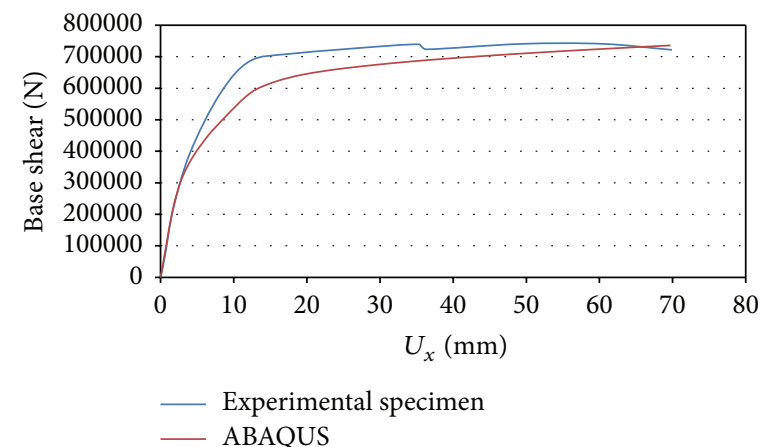

FIGURE 2: Load-displacement pushover curves of SPSWs specimens, from FEM analysis.

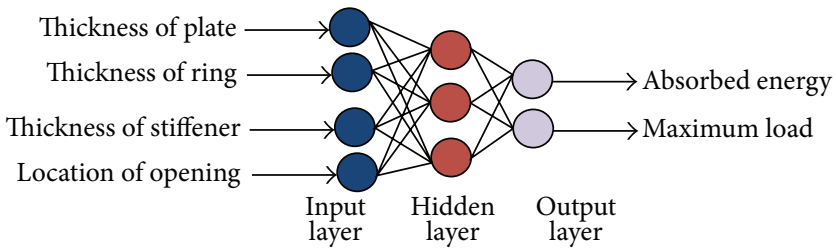

FIGURE 3: Architecture for the proposed MLP model.

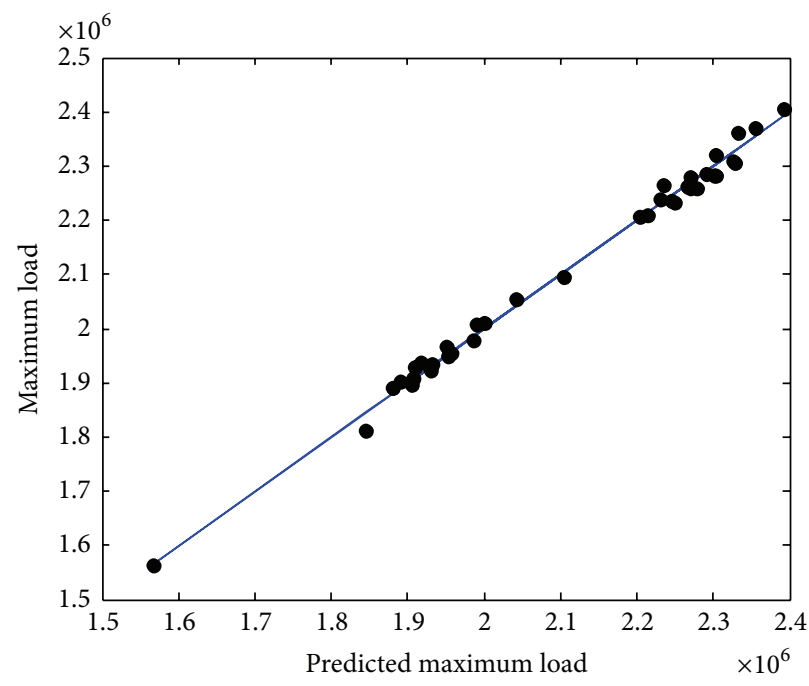

(a)

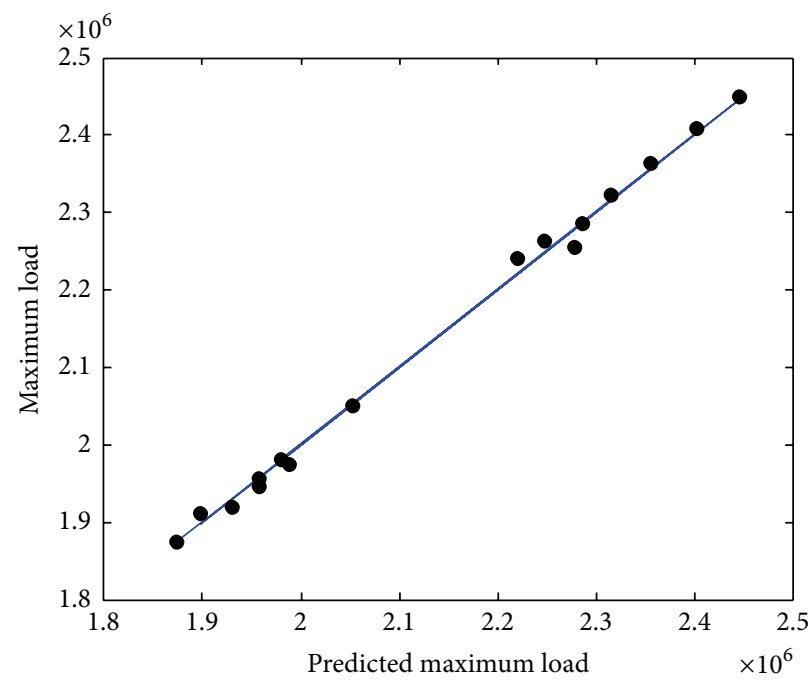

(b)

FIGURE 4: Regression diagrams of real and predicted results (using network) for (a) training data set and (b) testing data set: maximum load.

The experimental specimen SPSW in [12] is named SPSW4 and specified in Table I. The four-node shell elements with reduced integration (ABAQUS element S4R) method is used to model the frame beams, frame columns, and plate. Usage of this method reduces the analyzing time. The relationship of steel strain-stress is bilinear elastoplastic. The stiffeners are modeled using shell elements and the linear method is used to model the behavior of steel tip. The load-displacement results of the experimental specimen and simulation using ABAQUS are depicted in Figure 2. According to this figure, the simulation results have achieved good agreement with the experimental results. After verifying the analysis results in ABAQUS, the analytical specimens are defined and modeled.
In order to consider real condition, the wall height, wall width, plate thickness, and opening diameter were changed to $3.5 \mathrm{~m}, 4 \mathrm{~m}, 3 \mathrm{~mm}$, and $800 \mathrm{~mm}$, respectively.

\section{Artificial Neural Network}

ANNs can be defined as a mathematical system consisting of simple processing elements named neuron running in parallel, which can be generated as one or multiple layers [14]. Multilayer perceptron (MLP) networks are the most widely used ANNs [15]. The proposed MLP model is shown in Figure 3, where the inputs are thickness of plate $(\mathrm{mm})$, thickness of ring $(\mathrm{mm})$, thickness of stiffener $(\mathrm{mm})$, and 


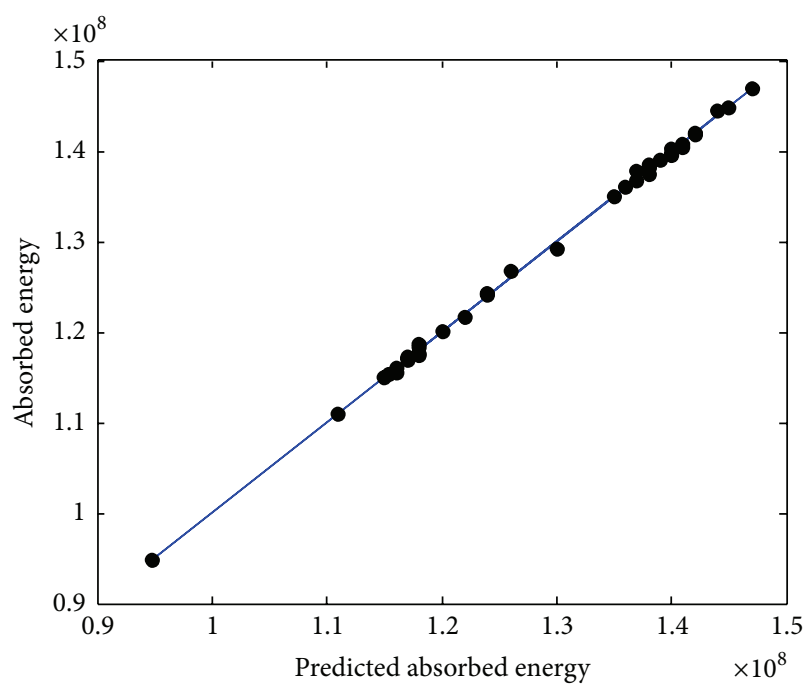

(a)

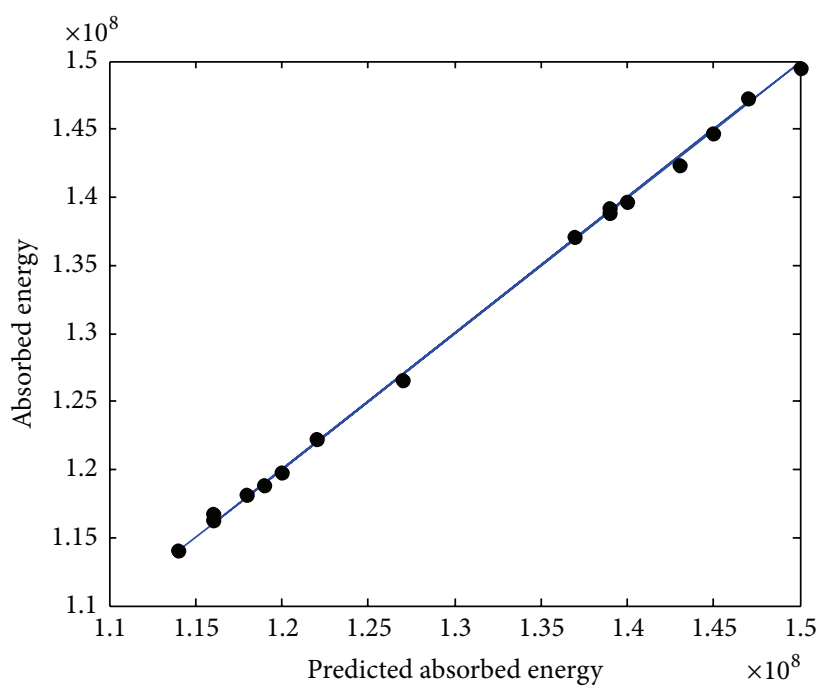

(b)

FIGURE 5: Regression diagrams of real and predicted results (using network) for (a) training data set and (b) testing data set: absorbed energy.
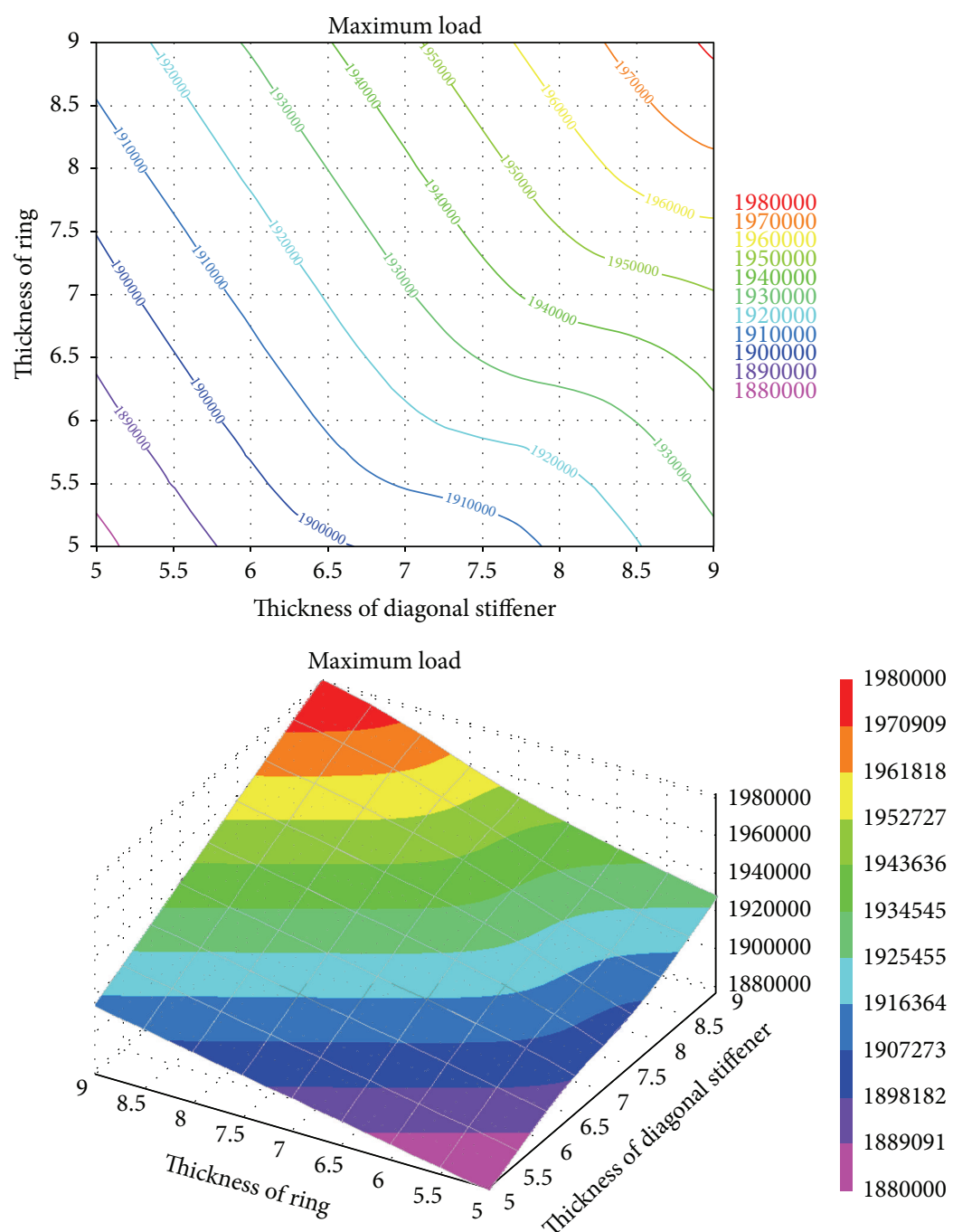

Figure 6: Obtained maximum load according to the thickness of ring and thickness of stiffener when the location of opening is down and thickness of plate is $1 \mathrm{~mm}$. 
TABLE 2: Specification of proposed ANN model.

\begin{tabular}{lc}
\hline Neural network & MLP \\
\hline Number of neurons in the input layer & 4 \\
Number of neurons in the first hidden layer & 3 \\
Number of neurons in the output layer & 2 \\
Number of epochs & 156 \\
Activation function of neurons in hidden layers & Tansig \\
Activation function of neurons in input and output layers & Purelin \\
Method of training & Levenberg-Marquardt \\
\hline
\end{tabular}
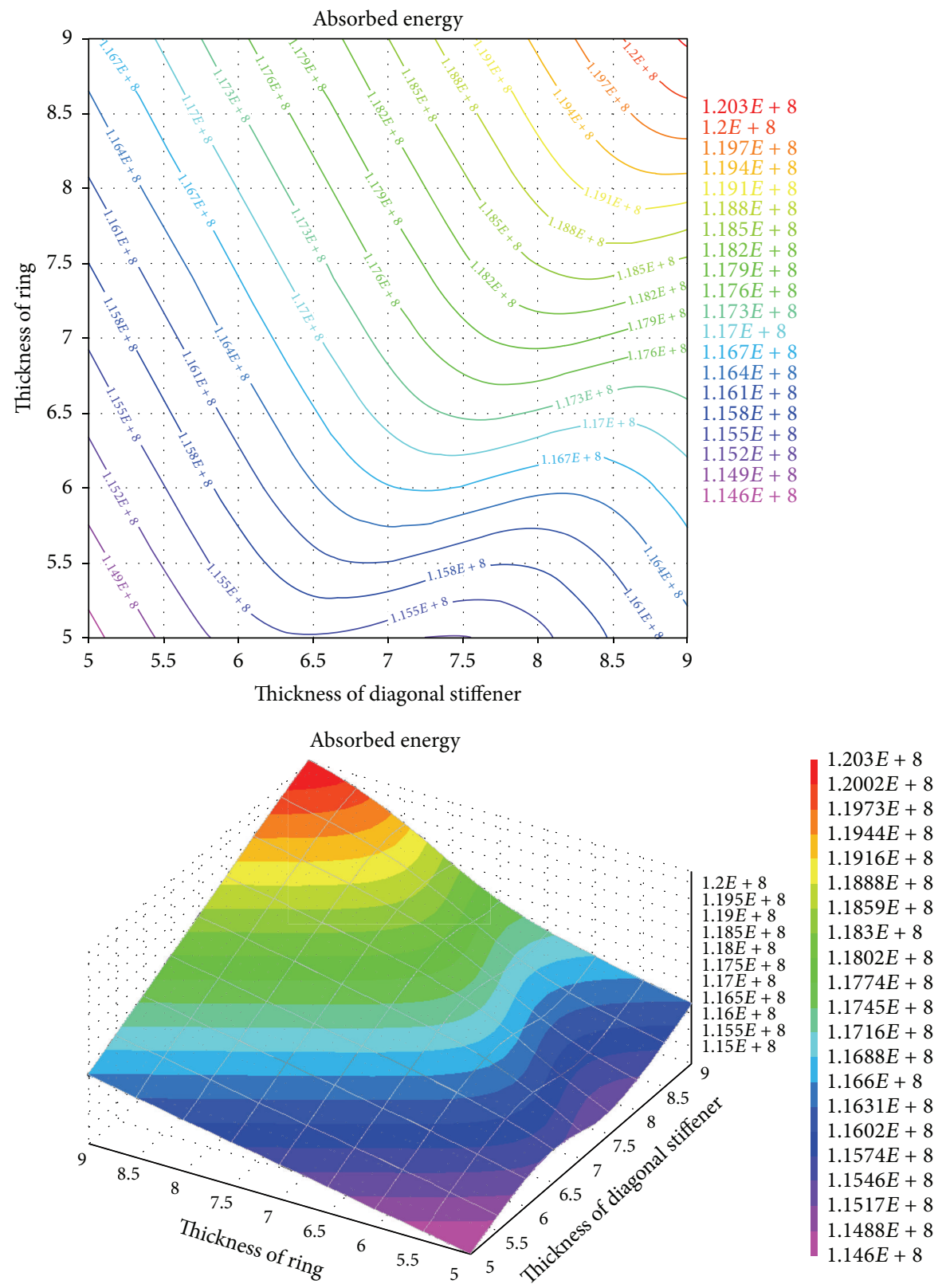

FIGURE 7: Obtained absorbed energy according to the thickness of ring and thickness of stiffener when the location of opening is down and thickness of plate is $1 \mathrm{~mm}$. 
TABLE 3: The used data in order to train the network.

\begin{tabular}{|c|c|c|c|c|c|c|c|}
\hline $\begin{array}{l}\text { Location of } \\
\text { opening* }\end{array}$ & $\begin{array}{c}\text { Thickness of } \\
\text { stiffener }\end{array}$ & $\begin{array}{c}\text { Thickness of } \\
\text { ring }\end{array}$ & $\begin{array}{c}\text { Thickness of } \\
\text { plate }\end{array}$ & $\begin{array}{l}\text { Maximum } \\
\text { load }\end{array}$ & $\begin{array}{l}\text { Absorbed } \\
\text { energy }\end{array}$ & $\begin{array}{l}\text { Predicted } \\
\text { maximum } \\
\text { load }\end{array}$ & $\begin{array}{c}\text { Predicted } \\
\text { absorbed } \\
\text { energy }\end{array}$ \\
\hline 1 & 7 & 5 & 1 & 1906303 & 115314602 & 1897583 & 115378114 \\
\hline 1 & 5 & 7 & 1 & 1890914 & $1.16 E+08$ & 1901224 & 115585841 \\
\hline 1 & 7 & 7 & 1 & 1929661 & $1.17 E+08$ & 1923935 & 116881630 \\
\hline 1 & 5 & 9 & 1 & 1908797 & $1.17 E+08$ & 1927556 & 117088592 \\
\hline 1 & 7 & 9 & 1 & 1953172 & $1.18 E+08$ & 1950142 & 118379679 \\
\hline 1 & 5 & 5 & 1.5 & 2203954 & $1.35 E+08$ & 2205809 & 135018526 \\
\hline 1 & 7 & 5 & 1.5 & 2246383 & $1.37 E+08$ & 2235881 & 136811127 \\
\hline 1 & 9 & 5 & 1.5 & 2279398 & $1.38 E+08$ & 2258219 & 138096462 \\
\hline 1 & 7 & 7 & 1.5 & 2265809 & $1.38 E+08$ & 2261716 & 138297657 \\
\hline 1 & 9 & 7 & 1.5 & 2303510 & $1.40 E+08$ & 2282393 & 139477386 \\
\hline 1 & 5 & 9 & 1.5 & 2236053 & $1.38 E+08$ & 2265018 & 138486054 \\
\hline 1 & 9 & 9 & 1.5 & 2327962 & $1.41 E+08$ & 2305837 & 140815014 \\
\hline 2 & 5 & 5 & 1 & 1567167 & 94752441 & 1563985 & 94759065 \\
\hline 2 & 7 & 5 & 1 & 1845458 & $1.11 E+08$ & 1810234 & 111000659 \\
\hline 2 & 5 & 7 & 1 & 1950168 & $1.22 E+08$ & 1965613 & 121659749 \\
\hline 2 & 7 & 7 & 1 & 2001327 & $1.24 E+08$ & 2010930 & 124277257 \\
\hline 2 & 9 & 7 & 1 & 2042962 & $1.26 E+08$ & 2055448 & 126835774 \\
\hline 2 & 5 & 9 & 1 & 1989923 & $1.24 E+08$ & 2007312 & 124066567 \\
\hline 2 & 9 & 9 & 1 & 2103724 & $1.30 E+08$ & 2096001 & 129159154 \\
\hline 2 & 5 & 5 & 1.5 & 2270495 & $1.40 E+08$ & 2278042 & 139699236 \\
\hline 2 & 9 & 5 & 1.5 & 2355397 & $1.45 E+08$ & 2368541 & 144896652 \\
\hline 2 & 5 & 7 & 1.5 & 2303318 & $1.42 E+08$ & 2319012 & 142046450 \\
\hline 2 & 5 & 9 & 1.5 & 2332584 & $1.44 E+08$ & 2359862 & 144386735 \\
\hline 2 & 7 & 9 & 1.5 & 2392523 & $1.47 E+08$ & 2404845 & 146970056 \\
\hline 3 & 5 & 5 & 1 & 1880428 & $1.15 E+08$ & 1888947 & 114924882 \\
\hline 3 & 7 & 5 & 1 & 1908229 & $1.16 E+08$ & 1909029 & 116070705 \\
\hline 3 & 9 & 5 & 1 & 1930187 & $1.17 E+08$ & 1929514 & 117239460 \\
\hline 3 & 7 & 7 & 1 & 1931633 & $1.18 E+08$ & 1932789 & 117426330 \\
\hline 3 & 9 & 7 & 1 & 1956552 & $1.18 E+08$ & 1953733 & 118621308 \\
\hline 3 & 5 & 9 & 1 & 1917767 & $1.18 E+08$ & 1936095 & 117615203 \\
\hline 3 & 9 & 9 & 1 & 1987000 & $1.20 E+08$ & 1979393 & 120097095 \\
\hline 3 & 5 & 5 & 1.5 & 2215179 & $1.36 E+08$ & 2208802 & 136062145 \\
\hline 3 & 7 & 5 & 1.5 & 2249024 & $1.38 E+08$ & 2233579 & 137513575 \\
\hline 3 & 5 & 7 & 1.5 & 2230472 & $1.37 E+08$ & 2237611 & 137750431 \\
\hline 3 & 7 & 7 & 1.5 & 2269430 & $1.39 E+08$ & 2259865 & 139020145 \\
\hline 3 & 9 & 7 & 1.5 & 2301572 & $1.40 E+08$ & 2282466 & 140309626 \\
\hline 3 & 7 & 9 & 1.5 & 2290581 & $1.41 E+08$ & 2286089 & 140516286 \\
\hline 3 & 9 & 9 & 1.5 & 2327089 & $1.42 E+08$ & 2309077 & 141827884 \\
\hline
\end{tabular}

${ }^{*} 1$ referred to down, 2 referred to middle, and 3 referred to up. 
TABLE 4: The used data in order to test the network.

\begin{tabular}{|c|c|c|c|c|c|c|c|}
\hline $\begin{array}{l}\text { Location of } \\
\text { opening* }^{*}\end{array}$ & $\begin{array}{c}\text { Thickness of } \\
\text { stiffener }\end{array}$ & $\begin{array}{c}\text { Thickness of } \\
\text { ring }\end{array}$ & $\begin{array}{c}\text { Thickness of } \\
\text { plate }\end{array}$ & $\begin{array}{l}\text { Maximum } \\
\text { load }\end{array}$ & $\begin{array}{l}\text { Absorbed } \\
\text { energy }\end{array}$ & $\begin{array}{l}\text { Predicted } \\
\text { maximum } \\
\text { load }\end{array}$ & $\begin{array}{c}\text { Predicted } \\
\text { absorbed } \\
\text { energy }\end{array}$ \\
\hline 1 & 9 & 7 & 1 & 1957395 & $1.18 E+08$ & 1946305 & 118157965 \\
\hline 1 & 5 & 7 & 1.5 & 2219737 & $1.37 E+08$ & 2240635 & 137094729 \\
\hline 2 & 9 & 5 & 1 & 1980587 & $1.22 E+08$ & 1980872 & 122175406 \\
\hline 2 & 7 & 9 & 1 & 2053128 & $1.27 E+08$ & 2051424 & 126599424 \\
\hline 2 & 9 & 7 & 1.5 & 2401916 & $1.47 E+08$ & 2409076 & 147218714 \\
\hline 1 & 7 & 9 & 1.5 & 2286001 & $1.40 E+08$ & 2285628 & 139661954 \\
\hline 1 & 9 & 9 & 1 & 1987718 & $1.20 E+08$ & 1974111 & 119765301 \\
\hline 3 & 5 & 9 & 1.5 & 2248066 & $1.39 E+08$ & 2263433 & 139223687 \\
\hline 3 & 9 & 5 & 1.5 & 2277673 & $1.39 E+08$ & 2256226 & 138811493 \\
\hline 2 & 7 & 7 & 1.5 & 2356185 & $1.45 E+08$ & 2364233 & 144643542 \\
\hline 3 & 7 & 9 & 1 & 1957027 & $1.19 E+08$ & 1957221 & 118822077 \\
\hline 3 & 5 & 7 & 1 & 1898122 & $1.16 E+08$ & 1912239 & 116253835 \\
\hline 2 & 9 & 9 & 1.5 & 2445879 & $1.50 E+08$ & 2449387 & 149527923 \\
\hline 2 & 7 & 5 & 1.5 & 2316077 & $1.43 E+08$ & 2323449 & 142307088 \\
\hline 1 & 9 & 5 & 1 & 1929052 & $1.16 E+08$ & 1920348 & 116676964 \\
\hline 1 & 5 & 5 & 1 & 1874102 & $1.14 E+08$ & 1874489 & 114060521 \\
\hline
\end{tabular}

${ }^{*} 1$ referred to down, 2 referred to middle, and 3 referred to up.

location of opening (up, middle, and down) and the outputs are absorbed energy and maximum load. by [16]

The input to the node $m$ in the first hidden layer is given

$$
\eta_{m}=\sum_{u=1}^{4}\left(X_{u} W_{u m}\right)+b_{m}, \quad m=1,2,3 .
$$

The output from $m$ th neuron of the hidden layer is given by

$$
U_{m}=f\left(\sum_{u=1}^{4}\left(X_{u} W_{u m}\right)+b_{m}\right), \quad m=1,2,3,
$$

where $X$ is the inputs, $b$ is the bias term, $W$ is the weighting factor, and $f$ is the activation function of the hidden layers.

There are a number of common activation functions in use with ANNs such as step function, tan-sigmoid function, and log-sigmoid function. A sigmoid function is a mathematical function having an " $\mathrm{S}$ " shape. In the presented architecture, tan-sigmoid was used as the activation function of the neurons in the hidden layers. By using the validated simulation, the data set required for training the network is obtained. The training of presented MLP networks is done by Levenberg-Marquardt (LM) algorithm. In this method, first derivative and second derivative (Hessian) are used for network weight correction [16]. The numbers of samples for training and testing data are 38 (about 70\%) and 16 (about $30 \%$ ), respectively. All of the input data were normalized to 1 and then applied to the neural network. In this study, different ANN structures were tested and optimized to obtain an efficient ANN configuration. Many different structures with one, two, and three hidden layers with different number of neurons in each layer were tested. MATLAB 7.0.4 software was used for training the ANN model. Table 2 shows the specification of the proposed ANN model.

\section{Results and Discussion}

Regression diagram is an appropriate diagram in order to show the ANN ability and usually the precision of the ANNs is indicated using this diagram. The more precise the network, the closer the data to the $x=y$ line. Regression diagrams of validated outputs and predicted ones (using network) for both outputs have been shown in Figures 4 and 5. The correlation coefficients of training and testing data for the first output (maximum load) are 0.9985 and 0.9981, respectively, and these coefficients for the second output (absorbed energy) are 0.9984 and 0.9975 . The comparison between real and predicted results has been tabulated for training and testing data in Tables 3 and 4, respectively.

From Tables 3 and 4 clearly the predicted absorbed energy as well as maximum load by ANN model is close to the validated simulation results. These results show the applicability of ANN as an accurate and reliable model for the prediction of absorbed energy and maximum load according to the thickness of plate $(\mathrm{mm})$, thickness of ring $(\mathrm{mm})$, thickness of stiffener ( $\mathrm{mm}$ ), and location of opening (up, middle, and down). Table 5 shows the obtained errors for the proposed ANN model, where the mean relative error percentage (MRE\%) and the root mean square error (RMSE) of the network are calculated by

$$
\mathrm{MRE} \%=100 \times \frac{1}{N} \sum_{j=1}^{N}\left|\frac{X_{j}(\text { Real })-X_{j}(\text { Pred })}{X_{j}(\text { Real })}\right|,
$$


TABLE 5: Obtained errors for training and testing results of the proposed ANN model.

\begin{tabular}{lcccc}
\hline Error & $\begin{array}{c}\text { Train } \\
\text { (maximum load) }\end{array}$ & $\begin{array}{c}\text { Test (maximum } \\
\text { load) }\end{array}$ & $\begin{array}{c}\text { Train } \\
\text { (absorbed energy) }\end{array}$ & $\begin{array}{c}\text { Test } \\
\text { (absorbed energy) }\end{array}$ \\
\hline RMSE & $1.4518 e-04$ & $1.0903 e-04$ & 0.0036 & 0.0035 \\
MRE\% & 0.0047 & 0.0712 & $7.6408 e-04$ & 0.0595 \\
\hline
\end{tabular}

$$
\mathrm{RMSE}=\left[\frac{\sum_{j=1}^{N}\left(X_{j}(\text { Real })-X_{j}(\text { Pred })\right)^{2}}{N}\right]^{0.5}
$$

where $N$ is the number of data and " $X$ (Real)" and " $X$ (Pred)" stand for validated simulation results (real) and predicted (ANN) values, respectively.

Figures 6 and 7 show the obtained maximum load and absorbed energy using the proposed ANN model for whole ring thicknesses and diagonal stiffener thicknesses when the opening is down and thickness of plate is $1 \mathrm{~mm}$.

\section{Conclusion}

ANN has many applications in civil engineering and is known as an efficient tool to handle problems of modeling and prediction. In this study, artificial neural network (ANN) is investigated to predict the maximum load and absorbed energy in the steel shear wall with the opening. To do this multilayer perceptron (MLP) neural network is used for developing the ANN model. The trained MLP network is able to predict the maximum load and absorbed energy with a mean relative error of $0.06 \%$.

\section{Competing Interests}

The authors declare that they have no competing interests.

\section{References}

[1] V. Caccese, M. Elgaaly, and R. Chen, "Experimental study of thin steel-plate shear walls under cyclic load," Journal of Structural Engineering, vol. 119, no. 2, pp. 573-588, 1993.

[2] R. G. Driver, G. L. Kulak, D. J. L. Kennedy, and A. E. Elwi, “Cyclic test of four-story steel plate shear wall," Journal of Structural Engineering, vol. 124, no. 2, pp. 112-120, 1998.

[3] A. S. Lubell, H. G. L. Prion, C. E. Ventura, and M. Rezai, "Unstiffened steel plate shear wall performance under cyclic loading," Journal of Structural Engineering, vol. 126, no. 4, pp. 453-460, 2000.

[4] M. Elgaaly, V. Caccese, and C. Du, "Postbuckling behavior of steel-plate shear walls under cyclic loads," Journal of Structural Engineering, vol. 119, no. 2, pp. 588-605, 1993.

[5] M. Elgaaly and Y. Liu, "Analysis of thin-steel-plate shear walls," Journal of Structural Engineering, vol. 123, no. 11, pp. 1487-1495, 1997.

[6] R. G. Driver, G. Kulak, A. E. Elwi, and L. Kennedy, "FE and simplified models of steel plate shear wall," Journal of Structural Engineering (ASCE), vol. 124, no. 2, pp. 121-130, 1997.

[7] J. Berman and M. Bruneau, "Plastic analysis and design of steel plate shear walls," Journal of Structural Engineering, vol. 129, no. 11, pp. 1448-1456, 2003.
[8] S. Sabouri-Ghomi, C. E. Ventura, and M. H. K. Kharrazi, "Shear analysis and design of ductile steel plate walls," Journal of Structural Engineering, vol. 131, no. 6, pp. 878-889, 2005.

[9] AISC, Seismic Provisions for Structural Steel Buildings, American Institute of Steel Construction, 2005.

[10] CSA, Limit States Design of Steel Structures for Buildings, Canadian Standards Association, 2009.

[11] S. Sabouri-Ghomi and S. R. A. Sajjadi, "Experimental and theoretical studies of steel shear walls with and without stiffeners," Journal of Constructional Steel Research, vol. 75, pp. 152-159, 2012.

[12] E. Alavi and F. Nateghi, "Experimental study on diagonally stiffened steel plate shear walls with central perforation," Journal of Constructional Steel Research, vol. 89, pp. 9-20, 2013.

[13] D. Dubina and F. Dinu, "Experimental evaluation of dual frame structures with thin-walled steel panels," Thin-Walled Structures, vol. 78, pp. 57-69, 2014.

[14] J. G. Taylor, Neural Networks and Their Applications, John Wiley \& Sons, West Sussex, UK, 1996.

[15] A. R. Gallant and H. White, "On learning the derivatives of an unknown mapping with multilayer feedforward networks," Neural Networks, vol. 5, no. 1, pp. 129-138, 1992.

[16] M. T. Hagan and M. B. Menhaj, "Training feedforward networks with the Marquardt algorithm," IEEE Transactions on Neural Networks, vol. 5, no. 6, pp. 989-993, 1994. 


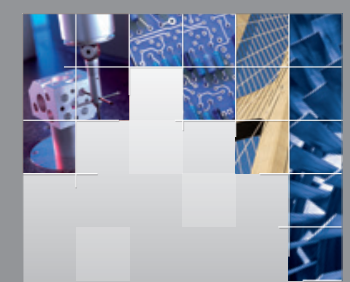

\section{Enfincering}
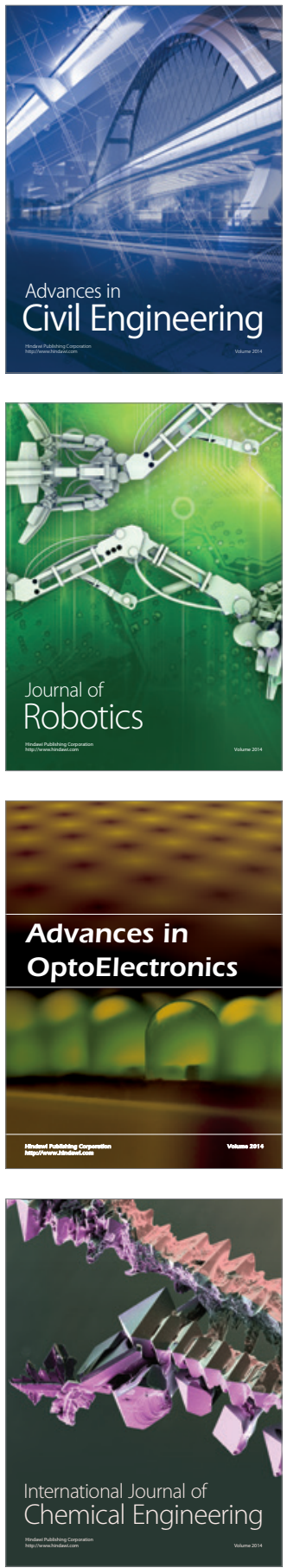

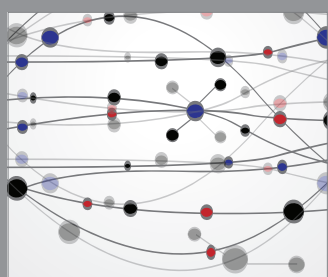

The Scientific World Journal

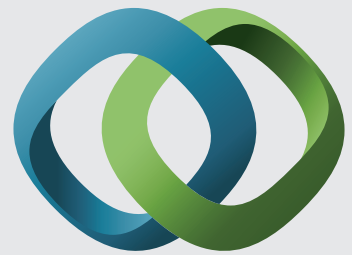

\section{Hindawi}

Submit your manuscripts at

http://www.hindawi.com
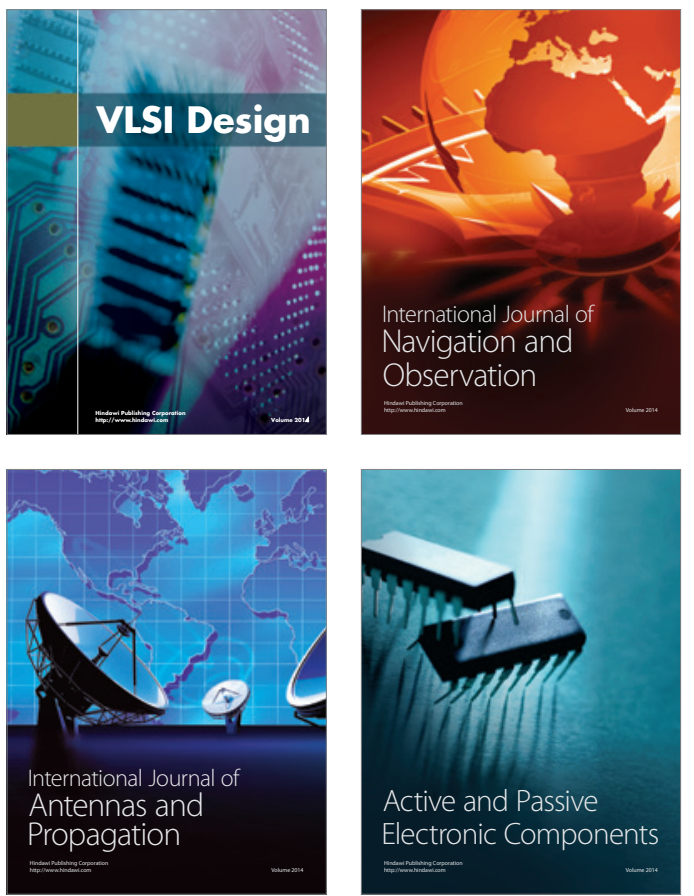
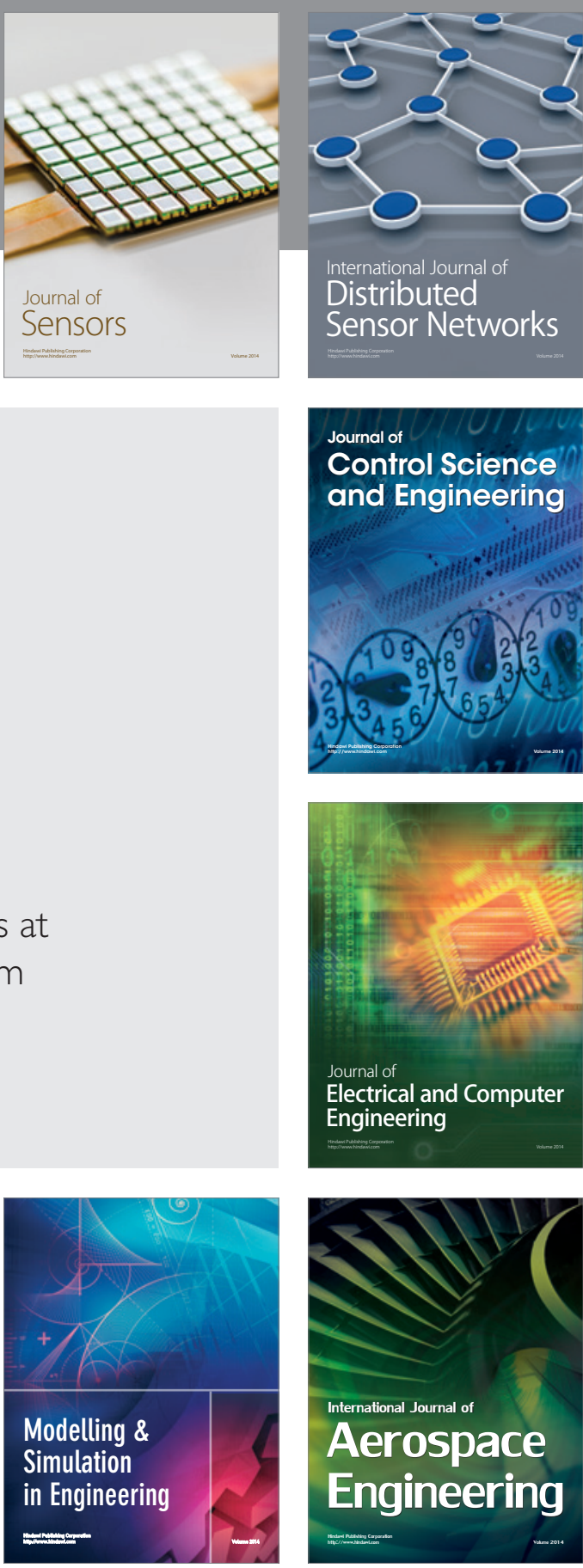

International Journal of

Distributed

Sensor Networks

Journal of

Control Science

and Engineering
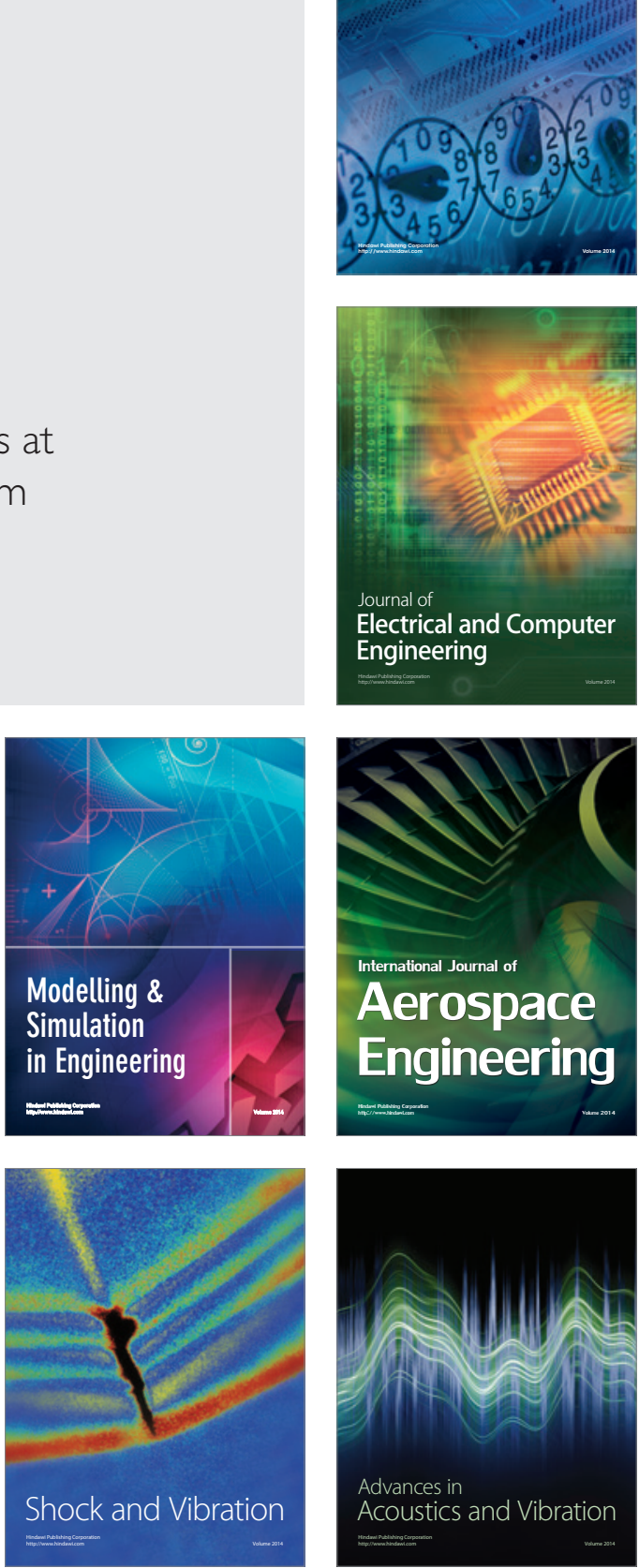